\title{
Foraging strategies of Adélie penguins: adjusting body condition to cope with environmental variability
}

\author{
Grant Ballard $^{1,2, *}$, Katie M. Dugger ${ }^{3}$, Nadav Nur ${ }^{1}$, David G. Ainley ${ }^{4}$ \\ ${ }^{1}$ PRBO Conservation Science, 3820 Cypress Drive \#11, Petaluma, California 94954, USA \\ ${ }^{2}$ School of Biological Sciences, University of Auckland, Auckland, New Zealand \\ ${ }^{3}$ Oregon State University, Department of Fisheries and Wildlife, 104 Nash Hall, Corvallis, Oregon 97331-3803, USA \\ ${ }^{4}$ H. T. Harvey \& Associates, 983 University Avenue, Bldg. D, Los Gatos, California 95032, USA
}

\begin{abstract}
Animals modulate breeding effort by balancing investment in self-maintenance against investment in their young, potentially impacting reproductive success when faced with difficult conditions. This life history trade-off model has been evaluated for flying birds, especially those that forage over large pelagic regions of relatively sparse prey availability. We evaluated its applicability to penguins which, lacking flight, depend on reliably available prey relatively close to colonies. We used transponders and an automated weighing system to monitor 40 to 75 breeding Adélie penguins Pygoscelis adeliae per season for 10 seasons, while environmental conditions varied dramatically, measuring foraging trip duration, parental mass change, and total food load delivered to chicks. Parents that lost the most mass during breeding provided more food to chicks while maintaining their own condition. In contrast, in years when adult mass was lower to begin with, parents recovered their own condition and delivered less food to chicks. Food loads were also related to environmental variables, with parents making longer trips and delivering less food when access to prey was more difficult, but delivering more food to 2-chick broods than to 1-chick broods. Penguins did not alternate between short (chick provisioning) and long (self-maintenance) trips, as has been observed in farranging seabirds. Nevertheless, our results indicate they regulated their condition depending on environmental and physiological factors, with impacts on the amount of food delivered to young and pre-fledging mass. Parental choice of multiple foraging habitats and depletion of prey in the nearest habitat due to intraspecific competition have important implications in explaining contrasting patterns observed among studies investigating the life history trade-off model in birds.
\end{abstract}

KEY WORDS: Adélie penguin · Adult condition · Chick provisioning · Environmental variability · Foraging effort · Foraging trip duration · Iceberg $\cdot$ Parental investment $\cdot$ Sea ice $\cdot$ Weighbridge

\section{INTRODUCTION}

Among central-place foraging species such as seabirds (Orians \& Pearson 1979), parents are challenged to provide for nutrient needs of rapidly growing young and simultaneously meet their own energetic requirements while foraging at a distance (Williams 1966, Stearns 1976, Ydenberg et al. 1994). If young are inadequately fed, their immediate (pre-departure) or subsequent (post-departure) survival may be at risk, but if parents do not adequately feed themselves, they risk their own survival and residual reproductive success (Erikstad et al. 1998, Golet et al. 1998, 2004, Weimerskirch et al. 2001). For long-lived species, even small reductions in adult survival as a trade-off for elevated breeding effort can have large impacts at the population level (Goodman 1974, Wooller \& Coulson 1977). Therefore, the frequency and duration of feeding trips, as well as food load size, are critical for both parent and young. 
Among birds, more feeding trips imply more food for offspring, but at greater energetic cost to the parent (Nur 1984a). Parents may use longer feeding trips to replenish their own reserves, but possibly at the expense of the chicks (Chaurand \& Weimerskirch 1994a, Weimerskirch et al. 1994, 2003). However, some flying birds may voluntarily sacrifice some of their own mass in order to decrease travel costs to foraging areas, thereby optimizing foraging efficiency (Freed 1981, Norberg 1981, but see Nur 1984b). The dilemma for the parent is particularly acute when environmental conditions or other factors reduce access to prey, and seabirds in general will favor their own survival at the expense of the chick, particularly in food-poor years (Goodman 1974). The idea that parents will adjust their reproductive tactics depending on their own condition and environmental factors has been referred to as the individual optimization hypothesis (Nur 1986) and has been described for volant landbirds as well as seabirds (Perrins \& Moss 1975, Chaurand \& Weimerskirch 1994b, Erikstad et al. 1997).

A model of optimal investment of parents feeding their young predicts that as prey availability or quality decreases, parents will partially compensate by working harder, but cannot afford to fully compensate (Nur 1987); thus the quantity and/or quality of food delivered to chicks is reduced, exemplifying a parent-offspring trade-off. In several seabird species, parents in good condition deliver more food than those in poor condition (Weimerskirch et al. 1994, Erikstad et al. 1997, Tveraa et al. 1998) and can do so while making shorter duration trips than parents in worse condition (Varpe et al. 2004).

A large body of work specific to these factors in longlived seabirds has focused primarily on flying species of high mobility, with morphology adapted towards maximizing flight efficiency (e.g. Pennycuick et al. 1984). These larids and procellarids are renowned for long-distance migration and foraging trips during breeding, including patterns of long versus short trips depending on whether parents needed to recover condition (e.g. Chastel et al. 1995a, b, Weimerskirch et al. 1997, 2000, 2001, Becker et al. 2001, Golet et al. 1998, 2004). A bimodal pattern, with parents making long self-maintenance trips and shorter chickprovisioning trips, has been described for several seabirds (Granadeiro et al. 1998, Weimerskirch 1998, Booth et al. 2000) and, in some cases, long and short trips alternated consecutively (Chaurand \& Weimerskirch 1994b, Weimerskirch et al. 1994). Bimodality in foraging trip duration has been linked to habitat availability because where only one habitat is available, species do not show bimodality (Weimerskirch et al. 1994). Environmental conditions also affect foraging trip patterns, with parents adopting a bimodal strategy when food was less accessible (Granadeiro et al. 1998). Further, longer trips appear to be triggered by lower body condition; a threshold body mass triggering longer trips has been posited for blue petrels Halobaena coerulea (Chaurand \& Weimerskirch 1994b) and sooty shearwaters Puffinus griseus (Weimerskirch 1998).

As a contrast to the work on flying species, penguins in general, and Adélie penguins Pygoscelis adeliae in particular, are tractable non-flying species with which to further investigate relationships among parental condition, provisioning behavior, and chick growth (Clarke 2001, Vleck \& Vleck 2002, Takahashi et al. 2003, Ropert-Coudert et al. 2004). Adélie penguins, because they must swim or walk to find food, are more reliant than flying species on predictable prey a comparatively short distance from the colony (Ainley 2002). Further, the Adélie is among the few highly migratory penguin species (Ballard et al. in press) that commonly raises 2 chicks to fledging; as such, the species may be particularly sensitive to variability in body condition or prey accessibility, since their reproductive output is double that of many other seabirds. Most other migratory penguins, like most pelagic seabirds, produce just 1 chick (Williams 1995). The more mobile seabirds, laying a single egg per breeding attempt, have been shown to have an energetic cushion, allowing for variation in prey availability and foraging strategies, whereby they can temporarily reduce their own condition in order to deliver sufficient food to their offspring (Lack 1968, Chaurand \& Weimerskirch 1994a, Weimerskirch et al. 1994).

It remains unclear to what extent penguins have such a cushion, and under what limits their chicks' survival becomes at risk. Watanuki et al. (2004) hypothesized that Adélie penguins might be constrained from adjusting (i.e. increasing) investment in their chicks in the face of challenging environmental conditions. A contrasting conclusion for Adélie penguins, consistent with flexible investment, has been postulated based on examination of diving behavior and foraging models (Ropert-Coudert et al. 2004). Furthermore, 3 empirical studies have found that Adélie penguins alternate long, relatively low-activity, self-maintenance trips with short, high-activity, chick-provisioning trips (Clarke 2001, Clarke et al. 2006, Angelier et al. 2008). Finally, Vleck \& Vleck (2002) showed that Adélie penguins with lower body mass at the onset of breeding were in poorer physiological condition and tended to have lower reproductive success than heavier individuals, and individuals with lower mass have elevated levels of corticosterone, suggesting they are more likely to abandon breeding efforts (Cockrem et al. 2006).

As a major habitat variable affecting penguin foraging and reproductive effort, sea ice coverage and prox- 
imity is important (Ainley 2002, Clarke et al. 2006, Cockrem et al. 2006, Emmerson \& Southwell 2008, Beaulieu et al. 2010). Given the choice, Adélie penguins feed in close proximity to sea ice, presumably because their preferred prey is found there, but potentially also because it offers a resting platform and easy source of drinking water (Ainley 2002). When sea ice is far from breeding colonies the penguins' foraging efficiency decreases, foraging effort increases, or both; parents undergo a severe loss in mass, less food is returned to chicks (Ainley et al. 1998), and prey type may shift (Ainley et al. 2003, Beaulieu et al. 2010). Alternatively, if there is insufficient open-water between floes, the presence of too much sea ice can present a physical barrier (Massom et al. 2006, Emmerson \& Southwell 2008). Previous studies of Adélie penguins found that foraging trip duration was longest, and breeding success lowest, in seasons when ice cover was greatest, but mechanistic linkages were not proposed (Clarke et al. 2002, Watanuki et al. 2002, 2004).

We report results of 10 years' investigation of the foraging behavior of 216 Adélie penguins at one of the world's largest Adélie breeding colonies (Ainley 2002) during a period of unprecedented environmental variability. Environmental conditions varied in part because of the presence of 2 very large icebergs (B-15 and C-16, as long as $175 \mathrm{~km}$ ) in the foraging area for half the study (2001-2005; Arrigo et al. 2002, Ainley et al. 2004, Shepherd et al. 2005; Fig. 1). While present, these icebergs restricted the normal movements of pack ice, resulting in higher spring/summer sea ice concentration that induced a regional, $40 \%$ reduction in primary productivity (Arrigo et al. 2002), and significantly less open water, thus reducing prey access by requiring more walking for penguins on foraging trips (as reviewed by Ainley 2002).

Here we tested 2 primary hypotheses: (1) the poorer the condition of a parent, the more it invests in its own self-maintenance with negative consequences to how much food is delivered to the young; and (2) under conditions of lower prey accessibility (higher energetic cost to parents per gram of food delivered), parents will make more investment in self-maintenance. To evaluate these hypotheses we tested 3 predictions. First, parents beginning a breeding season with more mass are more likely to lose mass during chick rearing; conversely, those that begin with lower mass are more likely to gain mass during chick rearing. Second, adult penguins in worse condition make longer foraging trips and deliver less food to young than those in better condition because of a need to maintain or regain condition; the latter need results in a bimodal distribution of long and short trips, which might be consecutive. And third, reduced access to prey due to higher than optimal sea ice concentration results in longer foraging

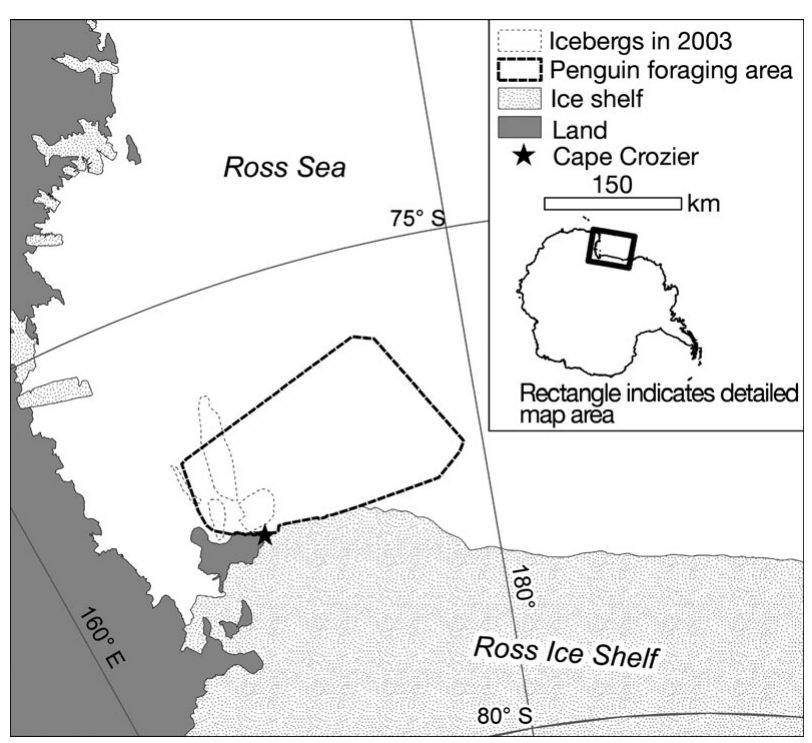

Fig. 1. Southern Ross Sea, Antarctica. Cumulative Adélie penguin foraging area (containing 95\% of all foraging positions) as determined from radio and satellite telemetry 1997 to 2006 and positions of giant icebergs (fragments of original B15 and C16) in 2003 to 2004 are indicated

trips and less food carried to young, with parents gaining mass instead, representing higher investment in parental condition, especially when there are 2 chicks instead of 1 and when chicks are older. We contrasted 5 stressful (iceberg, 2001 to 2005) with 5 less stressful (non-iceberg, 1997 to 2000, 2006) years with respect to Adélie penguin foraging behavior and the balance between self maintenance and chick rearing.

\section{MATERIALS AND METHODS}

The study was conducted at Cape Crozier, Ross Island, Antarctica (Fig. 1) during 10 breeding seasons, October to February in each case. We refer to each season by its initial year, i.e. $1997=1997-98$. Our study included all of the guard breeding stage (at least 1 parent always present) and three-fifths of the crèche stage (young can be left by both parents), 11 December to 20 January 1997 to 2006. One subcolony of $\sim 200$ (range 160 to 259) pairs in the Cape Crozier colony of 140000 pairs was encircled by a plastic fence. The only avenue in or out was over a weighbridge (WB) consisting of a scale, direction indicator (coupled photocells), and a radio-frequency identification reader connected to a data logger (Kerry et al. 1993, Ainley et al. 1998, Clarke et al. 1998, Ballard et al. 2001). In the WB subcolony, we implanted 216 (total across all years) penguins with a passively interrogated transponder (PIT) tag, which uniquely identified 
the bird each time it passed over the WB. The WB subcolony generally increased in size over the course of the study, coincident with increases in the overall Cape Crozier breeding population (Landcare Research unpubl. data). All PIT-tagged individuals were also banded with 1 stainless steel flipper band on the left flipper (details in Dugger et al. 2006). The number of actively breeding pairs with PIT tags each season ranged from 20 to 36 . Sex was primarily determined by copulatory position, but we also employed a combination of size (especially head and bill, Ainley \& Emison 1972) and behavior cues (e.g. timing of arrival to the colony, Ainley et al. 1983, Kerry et al. 1992) to discriminate sexes. All methods employed were approved by the Institutional Animal Care and Use committees of PRBO Conservation Science, H. T. Harvey and Associates, and Oregon State University.

The WB scale recorded 12 weights $\mathrm{s}^{-1}$. It automatically tared every 2 min to adjust for variation in snow, gravel, and other debris, and was accurate to $\pm 10 \mathrm{~g}$ when compared with known static weights (tested periodically during each year of the study). Penguin masses were calculated using an algorithm determined by finding the best model predicting known weights of penguins that had stopped on the scale $(\mathrm{n}=$ $6659 \pm 605$ ind. $\mathrm{yr}^{-1}$; model constructed using all penguins, not only PIT-tagged ones) and measured to within $0.02 \mathrm{~kg}$ (same mass reported at least 3 times consecutively). We applied this algorithm to all crossings that met the following conditions: maximum weight recorded was between 2.65 and $5.25 \mathrm{~kg}$ (less would be likely to be a chick and more would indicate multiple individuals, cf. Ainley \& Schlatter 1972, Ainley et al. 1998), number of weights recorded was at least 10, and the sixth weight recorded was greater than the first weight recorded. Variables considered in the model included the number of weights (i.e. how long the penguin was on the scale), each individual weight, the maximum weight, the median weight, and the difference between each individual weight and the first weight. The best model was determined by comparing Akaike's information criterion (AIC, Burnham \& Anderson 2002) values; parameters from the model with lowest AIC score were chosen. This was done for each year independently, since WB installation varied slightly out of necessity to accommodate for variable environmental conditions. WB masses were consistently lower but well-correlated with spring balance mass for individuals crossing the scale within $3 \mathrm{~d}$ of their initial PIT-tagging $(\mathrm{n}=18, \mathrm{r}=0.79, \mathrm{p}<0.001$, mean offset $=177 \pm 59 \mathrm{~g}$ ), so we added the mean offset between WB- and spring balance-derived mass to calculate the final mass used. These masses were within the range of those reported previously from extensive measurements made at Cape Crozier (Ainley 1972).
Adélie penguins at Cape Crozier have previously been found to have the lowest mass of all Ross Island penguins (i.e. compared with those from Cape Royds and Cape Bird, Ainley et al. 1998).

Parameters evaluated. From WB data we determined (for each foraging trip by each tagged individual) foraging trip duration, an index of the mass of food loads delivered to chicks, within-foraging trip mass change of the adult, and adult relative mass change since the beginning of the season. For each parent for each season we calculated its mass at the beginning of the chick provisioning period (note that this mass is expected to be lower than parental mass earlier in the breeding season, such as when adults first arrive to establish territories about 1.5 mo earlier). We also determined chick pre-fledging mass, sea ice concentration within the foraging area, and whether giant icebergs were present.

Foraging trip duration and number of trips: We measured foraging trip duration (FTD; definitions of all acronyms used can be found in Table 1) of birds known to be actively provisioning chicks. Visual inspection of the distribution of trip durations revealed that $95 \%$ were $>6 \mathrm{~h}$ in length. In order to avoid including penguins that were simply carrying rocks to nests or making other non-foraging excursions (Ballard et al. 2001), we excluded the shortest $5 \%$ (in duration) of trips. The number of trips is simply the number of foraging trips by a given individual between 21 December and 15 January, which is the period in which $95 \%$ of all breeding penguins were provisioning chicks.

Food loads (meals) to chicks: The mass of food delivered was calculated as the difference between individual parents' out-weight after food delivery and their preceding in-weight. This does not take into account any food used by the adult while attending their chicks during the guard stage, but we assumed this was negligible. This assumption is supported by previous analyses comparing WB food load estimates to results from stomach flushing (Clarke et al. 2002). Additionally, time spent in the colony between trips averaged only $0.83 \pm 0.02 d$, and during crèche stage, parents normally fed chicks and departed within a few hours. We were unable to assess the effect on our calculated food loads of differential amounts of water content or digestion, which may have varied with foraging trip duration or prey type. We calculated approximate total food delivered to chicks by each parent for the guard and crèche stages separately by using the mean load brought to the nest for each individual multiplied by the number of trips made by that individual. We were unable to use the actual value of food delivered because load sizes were not always calculable (the WB scale was subject to error due to multiple penguins on the scale at once, for example), while numbers of trips 
Table 1. Acronyms and brief descriptions of parameters measured and included in models describing foraging strategies of Adélie penguins at Cape Crozier

\begin{tabular}{|c|c|}
\hline $\begin{array}{l}\text { Abbreviation/ } \\
\text { acronym }\end{array}$ & Description \\
\hline brstage & Breeding stage; guard or crèche \\
\hline PFM & Pre-fledging mass; mass of chicks at $5 \mathrm{wk}(\mathrm{kg})$ \\
\hline foodload & Mass of food delivered to chicks, measured on each foraging trip (kg) \\
\hline FTD & Foraging trip duration (h) \\
\hline IC & Sea ice concentration ( $\%$ of foraging area covered by sea ice) \\
\hline iceberg & Y/N $;$ whether giant icebergs were present \\
\hline IM & Initial body mass; as measured in early guard stage \\
\hline n_chick & Number of chicks in nest (1 or 2 ) \\
\hline $\mathrm{RMC}_{\mathrm{i}}$ & $\begin{array}{l}\text { Relative mass change as a proportion of IM, measured upon initiation of each foraging trip; negative values } \\
\text { indicate mass gain }\end{array}$ \\
\hline $\mathrm{RMC}_{\mathrm{r}}$ & $\begin{array}{l}\text { Relative mass change as a proportion of IM, measured upon return from each foraging trip, after feeding } \\
\text { chicks; negative values indicate mass gain sex Female or male }\end{array}$ \\
\hline TFD & Total mass of food delivered to chicks for full season $(\mathrm{kg})$ \\
\hline WTMC & $\begin{array}{l}\text { Within trip mass change; difference between mass at return of trip after feeding chicks compared with mass } \\
\text { at beginning of trip, as a proportion of IM }\end{array}$ \\
\hline yr & Year, 1997 to 2006 (e.g. 1997 refers to the $1997-98$ breeding season) \\
\hline
\end{tabular}

was assessed accurately. Only parents that made $>1$ feeding trip during each breeding stage (guard and crèche) were included in the food load analysis.

Initial mass: For each individual we calculated their initial body mass (IM) during the season as the mean mass during the early guard period (on average 16 to 25 December: crèche date minus 15 to crèche date minus $6 \mathrm{~d}$, where crèche date occurs when $50 \%$ of nests in the subcolony entered crèche).

Within-trip mass change (WTMC) of adults: Adult mass change (tissue accumulation/reduction) within each foraging trip was calculated as the outbound mass (after feeding the chicks) minus the previous outbound mass of the parent. WTMC was divided by IM for all analyses, since the same absolute mass change for a large individual may be less consequential than for a smaller individual.

Relative mass change: We calculated a potential proxy for change in adult condition that we call relative mass change (RMC). RMC was assessed twice for each foraging trip (i.e. many times per individual per season): as $\mathrm{RMC}_{\mathrm{i}}$ (mass change at the time an individual initiated a trip) or $\mathrm{RMC}_{\mathrm{r}}$ (mass change at the time a foraging trip was completed, after chicks had been fed, i.e. at the time of departure for the subsequent foraging trip). Note that $\mathrm{RMC}_{\mathrm{r}}$ on one trip is the same as $\mathrm{RMC}_{\mathrm{i}}$ for the subsequent trip. Both were calculated as a proportion of IM. Before transformation (see 'Analyses'), positive values indicated that mass had been gained since early in the guard stage, and negative values that mass had been lost. We posit that individuals improve condition when initial condition is poorest; therefore, a gain in mass is associated with poor initial condition. To make the index more readily interpretable, and because Adélie penguins usually lost mass during chick rearing, as reported previously (e.g. Clarke 2001, Takahashi et al. 2003), we multiplied RMC (both measures) values by -1 , so that positive RMC values are presumed to be associated with good parental condition and negative values poor condition.

Chick pre-fledging mass: On average, chicks crèche at $23 \mathrm{~d}$ and fledge at $51 \mathrm{~d}$ (177 to 185, Ainley 2002). We assessed pre-fledging mass by weighing 50 chicks, selected randomly from subcolonies near the WB subcolony (minimizing disturbance to any single subcolony) in Week 5 (30 to $34 \mathrm{~d}$ past the colony's median hatch date), the age of heaviest mass (Ainley 2002).

Sea ice concentration and icebergs: We calculated the percent of the potential Crozier foraging area covered by sea ice as measured by weekly passive microwave imagery using the Special Sensor Microwave/Imager (SSMI, Cavalieri et al. 1996). The potential foraging area was determined as the polygon that contained $95 \%$ of at-sea positions of provisioning parents as determined by radio and satellite telemetry from 1997 to 2006 (Ainley et al. 2004, 2006, unpubl. data). Image resolution was $25 \mathrm{~km} \mathrm{pixel}^{-1}$. Higher resolution (12.5 $\mathrm{km} \mathrm{pixel}^{-1}$ ) microwave imagery using the Advanced Microwave Scanning Radiometer-EOS (AMSR-E, Cavalieri \& Comiso 2004) was available for only part of the study period (2002 onward), and values for these $5 \mathrm{yr}$ were very highly correlated with the SSMI-derived values $(r=0.99)$. Visual imagery at varying resolution (250 m to $1.5 \mathrm{~km} \mathrm{pixel}^{-1}$ ) was available 
but impossible to use consistently due to discontinuous cloud-free images. In order to assess consistent periods among years, we used sea ice concentration values for the same 7 dates each year: 17, 23, and 29 December, and $4,10,16$, and 22 January. All penguin foraging trips within the week centered on each of those dates were considered to have confronted the same sea ice concentration, which is the case at the scale that these measurements were taken (authors' pers. obs.).

Iceberg size was calculated using visual imagery from the Moderate Resolution Imaging Spectroradiometer (MODIS, $250 \mathrm{~m} \mathrm{pixel}^{-1}$, NASA 2007) on the same weekly basis as sea ice concentration, and the portion of the foraging area occupied by icebergs was considered unavailable for foraging penguins. Image analyses and foraging area polygon calculations were performed with ArcGIS 9.2 (ESRI). We evaluated 2 iceberg variables: presence/absence and amount of foraging area covered $\left(\mathrm{km}^{2}\right)$. In all tests, the presence/ absence of icebergs performed better than the iceberg area variable, so this is what we used in all results presented. However, the presence/absence variable only performed well as an explanatory variable if the 2000-2001 season was labeled as a 'no iceberg' year (the icebergs arrived after the crèche stage had begun, thus 2000-2001 was labeled 'no iceberg' in all analyses).

Analyses. We used generalized linear mixed models fitted using maximum likelihood, with individual treated as a random effect. This allowed use of unbalanced repeated measures of the same individuals within and between years (Bolker et al. 2009). We used an information-theoretic approach (Burnham \& Anderson 2002) to evaluate which of several competing models best predicted each dependent variable (linked to specific predictions and defined below). We included only covariates about which we either had specific predictions, or which we have previously shown to importantly influence the dependent variable in the given model (Ballard et al. 2001, Dugger et al. 2006, Lescroël et al. in press). Sex was included as a main effect because parental roles of Adélie penguins are distinctive by sex (Ainley et al. 1983, Chappell et al. 1993, Clarke et al. 1998, 2002, Ballard et al. 2001, Clarke 2001, Watanuki et al. 2004) and because there is ample evidence that, in birds in general, reproductive strategies of the sexes often differ (Lessells 1991). Residuals from models were normally distributed after specified (see below) transformations of the dependent variable, so Gaussian link functions were employed throughout. Each candidate model was ranked against the others in the set, examining each dependent variable separately using differences in the corrected $\mathrm{AIC}\left(\mathrm{AIC}_{\mathrm{c}}\right)$ and relative model weights (Burnham \& Anderson 2002). All models within 2 AIC $\left(\Delta_{i}\right)$ of the best model or contribut- ing to $90 \%$ of the summed model Akaike weights were considered as potentially relevant and examined further for implications of alternative interpretations. Reported effect sizes are estimates from the best model (the one contributing the highest Akaike weight) since our goal was not to find the best possible estimate for a given parameter but rather to evaluate which combination of parameters best predicted the dependent variable, with the expectation that different combinations would have different ecological implications (Burnham \& Anderson 2002). Standard errors and $95 \%$ confidence intervals were bootstrap-derived with 1000 repetitions, bias corrected (Rabe-Hesketh \& Skrondal 2008). All statistical calculations were performed using STATA (version 10.1, Stata Corp.). We present means and estimeates of effect $(\beta) \pm$ SE unless otherwise specified.

Below we elaborate on the predictions that we evaluated, with specific reference to the model sets we developed in each case. All predictions, including the predicted direction of each effect evaluated, are detailed in Table 2.

Prediction 1. Parents beginning a season with higher mass lose more mass during chick rearing: We evaluated whether $\mathrm{RMC}_{\mathrm{r}}$ at the 2 breeding stages during chick rearing was positive when parents started with higher IM and negative when parents had lower IM. The 2 stages were: (1) guard (crèche date minus 20 to crèche date minus 1 ) and (2) crèche (crèche date to crèche date plus 20). We expected that parents would begin to regain some mass during crèche, as reported previously (Clarke 2001), that females would be able to afford to lose proportionally less mass than males (presumably having invested more in breeding during the egg laying stage), and that there would be substantial annual variation. Thus the covariates considered included IM, breeding stage, year, and sex, with individual treated as a random effect.

Prediction 2.1. Parents in worse condition make longer foraging trips and carry smaller food loads while gaining mass for themselves: We evaluated 2 model sets, one with natural log-transformed foraging trip duration $(\ln [\mathrm{FTD}]$, Model 2.1.1) and the other with food load (Model 2.1.2) as the dependent variable. For each, we considered the same set of potential explanatory variables including condition at the beginning of the given foraging trip $\left(\mathrm{RMC}_{\mathrm{i}}\right)$, WTMC, breeding stage (guard or crèche), sex, and season, with individual treated as a random effect. We expected that trip duration would be longer during the crèche stage, that females would make longer trips, and that there would be substantial annual variation (Ballard et al. 2001, Dugger et al. 2006). We hypothesized that the number of chicks being fed would positively affect trip duration because it might take longer to find food sufficient for 
Table 2. Predictions regarding relationships between foraging parameters and covariates for Adélie penguins at Cape Crozier, Ross Island, Antarctica, 1997 to 2006. Primary effects (P) were those which we were most interested in evaluating relative to the given prediction; ancillary effects (A) were those which we expected to be influential but for which the outcomes did not bear directly on our main predictions

\begin{tabular}{|c|c|c|}
\hline General prediction & ependent variable & Structure of predicted effects \\
\hline $\begin{array}{l}\text { 1. Parents beginning a season heavier lose more } \\
\text { mass during chick rearing }\end{array}$ & $\mathrm{RMC}_{\mathrm{r}}$ & $\begin{array}{l}\text { P: } \beta_{\mathrm{IM}}>0 \\
\text { A: } \beta_{\text {brstage }}<0, \beta_{\mathrm{sex}(\mathrm{f})}<0, \beta_{\mathrm{yr}}(\text { variable })\end{array}$ \\
\hline $\begin{array}{l}\text { 2.1.1. Parents in worse condition make longer } \\
\text { foraging trips }\end{array}$ & $\ln (\mathrm{FTD})$ & $\begin{array}{l}\text { P: } \beta_{\mathrm{RMCi}}<0, \beta_{\mathrm{WTMC}}>0 \\
\text { A: } \beta_{\text {brstage }}>0, \beta_{\text {sex }(\mathrm{f})}>0, \beta_{\mathrm{n}_{\_} \text {chick }}>0, \beta_{\mathrm{yr}} \text { (variable) }\end{array}$ \\
\hline $\begin{array}{l}\text { 2.1.2. Parents in worse condition bring less food } \\
\text { while gaining mass for themselves }\end{array}$ & Foodload & $\begin{array}{l}\text { P: } \beta_{\mathrm{RMCi}}<0, \beta_{\mathrm{WTMC}}<0 \\
\text { A: } \beta_{\text {brstage }}>0, \beta_{\text {sex }(\mathrm{f})}<0, \beta_{\mathrm{n}_{\_} \text {chick }}>0, \beta_{\mathrm{yr}} \text { (variable) }\end{array}$ \\
\hline 2.2. Parents exhibit a bimodal distribution in trip duration & $\ln (\mathrm{FTD})$ & $\begin{array}{l}\text { P: } \beta_{\text {prevFTD }}<0 \\
\text { A: } \beta_{\text {RMCi }}<0, \beta_{\text {WTMC }}>0, \beta_{\text {brstage }}>0, \beta_{\text {sex }(\mathrm{f})}>0, \\
\beta_{n_{n} \text { chicks }}>0, \beta_{\text {year }} \text { (variable) }\end{array}$ \\
\hline $\begin{array}{l}\text { 2.3. A proportional mass threshold exists, below which a } \\
\text { parent will usually make a self-provisioning trip }\end{array}$ & WTMC & $\begin{array}{l}\mathrm{P}: \beta_{\mathrm{RMCi}}>0, \beta_{\mathrm{RMCi} 2}<0, \beta_{\mathrm{RMCi} 3}<0 \\
\mathrm{~A}: \beta_{\mathrm{IM}}<0, \beta_{\mathrm{sex}(\mathrm{f})}<0, \beta_{\mathrm{sex} \times \mathrm{RMCi}} \neq 0\end{array}$ \\
\hline $\begin{array}{l}\text { 3.1.1. High sea ice concentration and/or presence of giant } \\
\text { icebergs results in longer foraging trips }\end{array}$ & $\ln (\mathrm{FTD})$ & $\begin{array}{l}\text { P: } \beta_{\text {iceberg }}>0, \beta_{\text {IC }}<0, \beta_{\text {IC2 }}>0 \\
\text { A: } \beta_{\text {sex }(f)}>0, \beta_{\text {brstage }}>0, \beta_{\text {n_chick }}>0\end{array}$ \\
\hline $\begin{array}{l}\text { 3.1.2. High sea ice concentration and/or presence of giant } \\
\text { icebergs results in parents in poor condition }\end{array}$ & $\mathrm{RMC}_{\mathrm{r}}$ & $\begin{array}{l}\text { P: } \beta_{\text {iceberg }}<0, \beta_{\text {IC }}>0, \beta_{\text {IC2 }}>0 \\
\text { A: } \beta_{\text {IM }}>0, \beta_{\text {brstage }}<0, \beta_{\text {sex }(\mathrm{f})}<0, \beta_{\mathrm{n}_{\text {_chick }}}<0\end{array}$ \\
\hline $\begin{array}{l}\text { 3.2.1. High sea ice concentration and/or presence of giant } \\
\text { icebergs results in less food delivered to chicks }\end{array}$ & TFD & $\begin{array}{l}\text { P: } \beta_{\text {iceberg }}<0, \beta_{\text {IC }}>0, \beta_{\text {IC2 }}>0 \\
\text { A: } \beta_{\text {sex }(\mathrm{f})}<0, \beta_{n_{-} \text {chick }}>0\end{array}$ \\
\hline $\begin{array}{l}\text { 3.2.2. High sea ice concentration and/or presence of giant } \\
\text { icebergs results in lower pre-fledging mass }\end{array}$ & PFM & $\mathrm{P}: \beta_{\text {iceberg }}<0, \beta_{\mathrm{IC}}>0, \beta_{\mathrm{IC} 2}>0$ \\
\hline
\end{tabular}

2 chicks compared to 1 . We also expected that food loads would be larger during crèche because of larger chicks requiring more food, larger for 2-chick compared to 1-chick broods, and that females might carry less food because of their generally smaller size.

Prediction 2.2. Parents exhibit a bimodal distribution in trip duration: We evaluated whether there was any general bimodal pattern in FTD by visually inspecting the distributions of (untransformed) FTD for each individual each season and for all individuals within a season. Additionally, negative correlation between present and previous trip duration would indicate a pattern of consecutively alternating trip duration, whereas positive correlation would indicate that the longer a trip was, the longer the previous trip had been, and vice versa. Thus, using the best model predicting $\ln (\mathrm{FTD})$ from Prediction 2.1, we added $\ln$ (previous FTD).

Prediction 2.3. A proportional mass threshold exists, below which a parent will usually make a selfprovisioning trip: We assessed whether WTMC on each trip was an indication of whether the trip was selfprovisioning or not, i.e. did the adult gain mass for itself (i.e. not including the food delivered to chicks) on the trip or not? Individual was treated as a random effect, and with WTMC on the trip as the dependent variable, we looked for best predictors among the following covariates: adult condition $\left(\mathrm{RMC}_{\mathrm{i}}\right)$ and non-linearities (which would reveal changes in the magnitude of the effect) in the effect of adult condition by including the quadratic $\left(\mathrm{RMC}_{\mathrm{i}}{ }^{2}\right)$ and cubic $\left(\mathrm{RMC}_{\mathrm{i}}{ }^{3}\right)$ terms of the $\mathrm{RMC}_{\mathrm{i}}$ covariate. The rationale for inclusion of these non-linear structures was that the relationship between WTMC and $\mathrm{RMC}_{\mathrm{i}}$ may reflect thresholds in the amount of mass that could be gained or lost by an individual. We predicted that the cubic term in particular might be important because we posited that WTMC could reach both an upper and lower limit, above or below which no more mass could be gained or lost on a given trip. Because we expected that this effect might be stronger in females than males (i.e. that a female in the same relatively poor condition might be more likely to make a self provisioning trip than a male in the same relative condition, cf. Clarke 2001) we added the interaction of sex with the highest order polynomial of $\mathrm{RMC}_{\mathrm{i}}$ that was retained to see if it improved the model. We also expected that individuals starting with higher IM would have lower WTMC because they presumably had more reserves to trade against, so IM was included as a covariate.

Prediction 3.1. High sea ice concentration and/or presence of giant icebergs result in longer foraging trips and parents returning from foraging trips in poorer condition, especially when there were 2 chicks to feed or when chick needs were greater, later in the season: We evaluated 2 model sets for 2 dependent variables: Model 3.1.1 for $\ln ($ FTD) and Model 3.1.2 for $\mathrm{RMC}_{\mathrm{r}}$. For both we evaluated the individual 
and combined additive effects of sea ice concentration, presence of icebergs, breeding stage (guard, crèche), number of chicks, and sex, with individual treated as a random effect. Predicted effects for Model 3.1.1 were as for previous FTD models and those for Model 3.1.2 were as for the previous $\mathrm{RMC}_{\mathrm{r}}$ model (see 'Prediction 1') except we excluded season because sea ice concentration and iceberg presence/ absence did not vary much (or at all) intra-annually compared with interannually. We also added the number of chicks being fed to Model 3.1.2 because we were interested in the effect of challenges to parents on their condition, predicting that having 2 chicks would have negative consequences. In both model sets we included the potential for non-linear effects in sea ice concentration by evaluating the quadratic term (sea ice concentration) ${ }^{2}$. In other words, we predicted that both too much and too little sea ice could have negative effects on foraging trip duration and condition of adult Adélie penguins. For the $\mathrm{RMC}_{\mathrm{r}}$ models we included IM as a covariate, and for both models individual was treated as a random effect.

Prediction 3.2. High sea ice concentration and/or presence of giant icebergs result in less food delivered to chicks and lower pre-fledging mass: We evaluated 2 model sets, one for total food delivered (only included parents who crèched at least 1 chick in a given season, Model 3.2.1) and another for prefledging mass (Model 3.2.2). For each, we examined the individual and additive effects of sea ice concentration and presence of icebergs. As previously, (sea ice concentration $)^{2}$ was included in both models because we expected that a certain amount of sea ice should be beneficial to amount of food delivered and prefledging mass, but that too much sea ice could be detrimental. Individual was included as a random effect in Model 3.2.1 since most individuals were present in at least 2 of the $10 \mathrm{yr}$. Additionally, we expected food delivery to be higher to 2-chick broods than 1-chick broods, and that females might bring less total food than males due to their smaller size.

\section{RESULTS}

\section{Prediction 1}

Mean IM varied from $3.40 \pm 0.08 \mathrm{~kg}$ (1997) to $4.04 \pm$ $0.07 \mathrm{~kg}$ (1999) and females were lighter than males in every year (Table 3). The best model predicting $\mathrm{RMC}_{\mathrm{r}}$ included the covariates IM, sex, year, and breeding stage (Table 4). For every kilogram of extra IM, individuals on average lost an extra $20.0 \pm 1.8 \%$ of their initial body mass during chick rearing. Females lost $5.4 \pm 1.2 \%$ more proportional weight than males (counter to our expectation), and parents measured during crèche had regained $0.99 \pm 0.51 \%$ of the mass they had lost during the guard stage (Table 5). $\mathrm{RMC}_{\mathrm{r}}$ as measured during crèche was positive in 9 of 10 seasons, meaning that parents usually lost mass during chick rearing. However, in 1997, when IM (especially in females) was lowest, RMC values (before controlling for IM in the model) were negative, meaning that adults gained mass during chick rearing (Table 3 ).

\section{Prediction 2.1}

Parents who made longer trips and brought back smaller food loads gained more mass (higher WTMC), and parents with lower RMC brought back less food (Figs. 2 \& 3, Table 5). However, parents in worse condition did not make longer trips, as predicted. While $\mathrm{RMC}_{\mathrm{i}}$ was retained in the third strongest model, the $95 \% \mathrm{CI}$ around the estimate of its effect included zero, indicating a very weak effect $\left(\Delta_{\mathrm{i}}=2.06,15.0 \%\right.$ of $\mathrm{AIC}_{\mathrm{C}}$ weight, $\beta=-0.020,95 \% \mathrm{CI}=-0.495$ to 0.455 ; Table 4$)$.

The best model for FTD suggested that females made trips $1.25 \mathrm{~h}$ longer (95\% CI $=1.13$ to 1.38$)$ than males, there was substantial annual variation in FTD, and trips were $1.16 \mathrm{~h}$ longer $(95 \% \mathrm{CI}=1.08$ to 1.25$)$ during crèche than the guard stage (Table 5). In addition, for every $10 \%$ increase in WTMC, trip duration was extended by $1.08 \mathrm{~h}(95 \% \mathrm{CI}=1.41$ to 3.03$)$. WTMC, sex, year, and breeding stage were included in both competitive FTD models, and the number of 
Table 4. Model selection results for each prediction as evaluated by comparing differences and weights as determined using corrected Akaike's information criterion $\left(\mathrm{AIC}_{\mathrm{c}}\right)$. All models that contributed to $90 \%$ of the summed $\mathrm{AIC}_{\mathrm{c}}$ model weights, as well as intercept only models, are shown. All possible combinations of terms that were included in each model set (different for each prediction) were evaluated. Number of estimated parameters (K), number of observations (n), and difference in model $\mathrm{AIC}_{\mathrm{c}} \mathrm{value}$ from the best model $\left(\Delta \mathrm{AIC}_{\mathrm{c}}\right)$ are shown for each model. All models except Model 3.2.2 included individual as a random effect. See Table 1 for parameter definitions

\begin{tabular}{|c|c|c|c|c|}
\hline Model & $\begin{array}{c}\text { Log } \\
\text { likelihood }\end{array}$ & $\mathrm{K}$ & $\begin{array}{c}\Delta \\
\mathrm{AIC}_{\mathrm{C}}{ }^{1}\end{array}$ & $\begin{array}{c}\mathrm{AIC}_{\mathrm{c}} \\
\text { weight }\end{array}$ \\
\hline \multicolumn{5}{|l|}{ 1. $\mathbf{R M C}_{\mathbf{r}}(\mathrm{n}=1321)$} \\
\hline $\mathrm{IM}+\mathrm{yr}+\mathrm{sex}+$ brstage & 1568.122 & 15 & 0.000 & 0.738 \\
\hline $\mathrm{IM}+\mathrm{yr}+\mathrm{sex}$ & 1565.880 & 14 & 2.439 & 0.218 \\
\hline Intercept only & 1300.284 & 3 & 511.327 & 0.000 \\
\hline \multicolumn{5}{|l|}{ 2.1.1 Ln(FTD) $(\mathrm{h}, \mathrm{n}=986)$} \\
\hline $\mathrm{WTMC}+\mathrm{sex}+\mathrm{yr}+$ brstage $+\mathrm{n} \_$chick & -674.308 & 16 & 0.000 & 0.421 \\
\hline WTMC + sex + yr + brstage & -675.656 & 15 & 0.631 & 0.307 \\
\hline $\mathrm{WTMC}+\mathrm{sex}+\mathrm{yr}+$ brstage + n_chick $+\mathrm{RMC}_{\mathrm{i}}$ & -674.304 & 17 & 2.064 & 0.150 \\
\hline $\mathrm{WTMC}+\mathrm{sex}+\mathrm{yr}+$ brstage $+\mathrm{RMC}_{\mathrm{i}}$ & -675.654 & 16 & 2.692 & 0.110 \\
\hline Intercept only & -785.518 & 3 & 195.885 & 0.000 \\
\hline \multicolumn{5}{|l|}{ 2.1.2 Foodload $(\mathrm{kg}, \mathrm{n}=754)$} \\
\hline $\mathrm{RMC}_{\mathrm{i}}+\mathrm{WTMC}+\mathrm{yr}+\mathrm{n} \_$chick & -84.880 & 15 & 0.000 & 0.268 \\
\hline $\mathrm{RMC}_{\mathrm{i}}+\mathrm{WTMC}+\mathrm{yr}+\mathrm{n} \_$chick + sex & -84.018 & 16 & 0.362 & 0.224 \\
\hline $\mathrm{RMC}_{\mathrm{i}}+\mathrm{WTMC}+\mathrm{yr}$ & -86.598 & 14 & 1.353 & 0.136 \\
\hline $\mathrm{RMC}_{\mathrm{i}}+\mathrm{WTMC}+\mathrm{yr}+\mathrm{sex}$ & -85.677 & 15 & 1.593 & 0.121 \\
\hline $\mathrm{RMC}_{\mathrm{i}}+\mathrm{WTMC}+\mathrm{yr}+\mathrm{n} \_$chick + brstage & -84.755 & 16 & 1.836 & 0.107 \\
\hline $\mathrm{RMC}_{\mathrm{i}}+\mathrm{WTMC}+\mathrm{yr}+\mathrm{n}$ _chick + brstage + sex & -83.868 & 17 & 2.156 & 0.091 \\
\hline Intercept only & -165.511 & 3 & 138.643 & 0.000 \\
\hline \multicolumn{5}{|l|}{2.3 WTMC $(n=1068)$} \\
\hline $\mathrm{Sex}+\mathrm{IM}+\mathrm{RMC}_{\mathrm{i}}+\mathrm{RMC}_{\mathrm{i}}^{2}+\mathrm{RMC}_{\mathrm{i}}^{3}$ & 1449.209 & 8 & 0.000 & 0.705 \\
\hline $\mathrm{Sex}+\mathrm{IM}+\mathrm{RMC}_{\mathrm{i}}+\mathrm{RMC}_{\mathrm{i}}^{2}+\mathrm{RMC}_{\mathrm{i}}^{3}+\operatorname{sex} \times \mathrm{RMC}_{\mathrm{i}}^{3}$ & 1449.216 & 9 & 2.021 & 0.257 \\
\hline Intercept only & 1301.857 & 3 & 284.590 & 0.000 \\
\hline \multicolumn{5}{|l|}{ 3.1.1 $\ln ($ FTD $)(h, n=2388)$} \\
\hline Iceberg $+\mathrm{IC}+\mathrm{IC}^{2}+$ sex + brstage $+\mathrm{n} \_$chick & -1687.135 & 9 & 0.000 & 0.505 \\
\hline Iceberg $+\mathrm{IC}+\mathrm{IC}^{2}+$ sex + brstage & -1688.161 & 8 & 0.038 & 0.495 \\
\hline Intercept only & -1807.120 & 3 & 227.904 & 0.000 \\
\hline \multicolumn{5}{|l|}{ 3.1.2 $\mathbf{R M C}_{\mathbf{r}}(\mathrm{n}=1321)$} \\
\hline $\mathrm{IM}+$ sex + brstage + iceberg & 1564.984 & 7 & 0.000 & 0.257 \\
\hline $\mathrm{IM}+$ sex + brstage + iceberg $+\mathrm{n} \_$chick & 1565.719 & 8 & 0.553 & 0.194 \\
\hline $\mathrm{IM}+$ sex + brstage + iceberg + IC & 1565.674 & 8 & 0.644 & 0.186 \\
\hline $\mathrm{IM}+$ sex + brstage + iceberg + n_chick $+\mathrm{IC}$ & 1566.588 & 9 & 0.843 & 0.168 \\
\hline $\mathrm{IM}+\mathrm{sex}+$ iceberg & 1562.876 & 6 & 2.195 & 0.086 \\
\hline $\mathrm{IM}+$ sex + brstage + iceberg + n_chick $+\mathrm{IC}+\mathrm{IC}^{2}$ & 1565.739 & 9 & 2.541 & 0.075 \\
\hline Intercept only & 1300.284 & 3 & 521.332 & 0.000 \\
\hline \multicolumn{5}{|l|}{ 3.2.1 TFD $(\mathrm{kg}, \mathrm{n}=187)$} \\
\hline $\mathrm{n} \_$chick + iceberg $+\mathrm{IC}+\mathrm{IC}^{2}$ & -437.865 & 6 & 0.000 & 0.733 \\
\hline n_chick + iceberg $+\mathrm{IC}+\mathrm{IC}^{2}+\operatorname{sex}$ & -437.887 & 7 & 2.204 & 0.243 \\
\hline Intercept only & -458.100 & 3 & 34.135 & 0.000 \\
\hline \multicolumn{5}{|l|}{ 3.2.2 PFM (kg, n=501) } \\
\hline Iceberg IC & -3927.530 & 3 & 0.000 & 0.728 \\
\hline Iceberg IC IC ${ }^{2}$ & -3927.497 & 4 & 1.967 & 0.272 \\
\hline Intercept only & -4003.179 & 1 & 147.257 & 0.000 \\
\hline
\end{tabular}

chicks being fed was included in the best model, but the confidence interval for this estimate included zero $(\beta=-0.076,95 \% \mathrm{CI}=-0.193$ to 0.042$)$; thus the strength of this effect was weak.

There were several competitive models relating covariates of interest to food loads brought to chicks; however, $\mathrm{RMC}_{\mathrm{i}}, \mathrm{WTMC}$, and year were always in- cluded in the top models. Together these 7 models accounted for $100 \%$ of the total model weight (Table 4). Every $10 \%$ decrease in relative mass (i.e. increase in $\mathrm{RMC}_{\mathrm{i}}$ ) resulted in $130.8 \pm 2.3 \mathrm{~g}$ more food (Fig. 3b, Table 5), and every $10 \%$ increase in WTMC resulted in $184.1 \pm 2.1 \mathrm{~g}$ less food delivered to chicks. The effects of sex (second best model, $\Delta_{\mathrm{i}}=0.36,22.4 \%$ 
Table 5. Estimated coefficients of effects and bootstrapped confidence intervals for the selected model for each prediction. See Table 1 for parameter definitions

\begin{tabular}{|c|c|c|c|c|}
\hline \multirow{2}{*}{$\begin{array}{l}\begin{array}{c}\text { Prediction } \\
\text { Model }\end{array} \\
1\end{array}$} & \multirow[t]{2}{*}{ Parameter } & \multirow[t]{2}{*}{ Coefficient } & \multicolumn{2}{|c|}{$95 \% \mathrm{CI}$} \\
\hline & & & & \\
\hline \multirow[t]{5}{*}{$\mathrm{RMC}_{\mathrm{r}}$} & IM (kg) & 0.200 & 0.165 & 0.235 \\
\hline & brstage & -0.010 & -0.020 & 0.000 \\
\hline & $\operatorname{sex}=F$ & 0.054 & 0.030 & 0.077 \\
\hline & yr & (9 estimates) & & \\
\hline & Intercept & -0.710 & -0.823 & -0.596 \\
\hline \multicolumn{5}{|l|}{2.1 .1} \\
\hline \multirow[t]{6}{*}{$\ln (\mathrm{FTD})(\mathrm{h})$} & $\mathrm{WTMC}^{*}$ & 0.724 & 0.342 & 1.107 \\
\hline & $\operatorname{sex}=F$ & 0.220 & 0.121 & 0.319 \\
\hline & brstage & 0.152 & 0.079 & 0.226 \\
\hline & n_chick & -0.076 & -0.192 & 0.040 \\
\hline & yr & (9 estimates) & & \\
\hline & Intercept & 3.230 & 3.019 & 3.441 \\
\hline \multicolumn{5}{|l|}{2.1 .2} \\
\hline \multirow[t]{5}{*}{ Foodload (kg) } & $\mathrm{RMC}_{\mathrm{i}}$ & 1.308 & 0.866 & 1.749 \\
\hline & WTMC & -1.841 & -2.259 & -1.424 \\
\hline & n_chick & 0.057 & -0.002 & 0.117 \\
\hline & yr & (9 estimates) & & \\
\hline & Intercept & 0.530 & 0.408 & 0.653 \\
\hline \multicolumn{5}{|l|}{2.2} \\
\hline \multirow[t]{6}{*}{$\ln (\mathrm{FTD})(\mathrm{h})$} & $\ln ($ prev FTD) & 0.239 & 0.113 & 0.365 \\
\hline & WTMC & 0.850 & 0.369 & 1.330 \\
\hline & $\operatorname{sex}=F$ & 0.164 & 0.083 & 0.246 \\
\hline & brstage & 0.165 & 0.078 & 0.252 \\
\hline & n_chick & -0.122 & -0.211 & -0.033 \\
\hline & $\begin{array}{c}\mathrm{yr} \\
\text { Intercept }\end{array}$ & $\begin{array}{c}\text { (9 estimates) } \\
2.527\end{array}$ & 2.076 & 2977 \\
\hline \multicolumn{5}{|l|}{2.3} \\
\hline \multirow[t]{6}{*}{ WTMC } & $\operatorname{sex}=F$ & -0.030 & -0.046 & -0.015 \\
\hline & IM & -0.122 & -0.147 & -0.097 \\
\hline & $\mathrm{RMC}_{\mathrm{i}}$ & 0.671 & 0.555 & 0.786 \\
\hline & $\mathrm{RMC}_{\mathrm{i}}^{2}$ & -0.264 & -0.704 & 0.176 \\
\hline & $\mathrm{RMC}_{\mathrm{i}}^{3}$ & -1.913 & -3.926 & 0.100 \\
\hline & Intercept & 0.438 & 0.345 & 0.530 \\
\hline \multicolumn{5}{|l|}{3.1 .1} \\
\hline \multirow[t]{6}{*}{$\ln (\mathrm{FTD})(\mathrm{h})$} & $\operatorname{sex}=F$ & 0.224 & 0.138 & 0.310 \\
\hline & brstage & 0.112 & 0.058 & 0.166 \\
\hline & IC & -0.051 & -0.074 & -0.028 \\
\hline & $\mathrm{IC}^{2}$ & 0.002 & 0.001 & 0.002 \\
\hline & iceberg $=\mathrm{Y}$ & 0.396 & 0.239 & 0.553 \\
\hline & Intercept & 3.164 & 3.064 & 3.263 \\
\hline \multicolumn{5}{|l|}{3.1 .2} \\
\hline \multirow[t]{5}{*}{$\mathrm{RMC}_{\mathrm{r}}{ }^{*}$} & Sex $=F$ & 0.195 & 0.175 & 0.215 \\
\hline & IM & 0.052 & 0.031 & 0.073 \\
\hline & Brstage & 0.010 & 0.000 & 0.020 \\
\hline & iceberg $=\mathrm{Y}$ & 0.024 & 0.012 & 0.036 \\
\hline & Intercept & -0.697 & -0.617 & -0.777 \\
\hline \multicolumn{5}{|l|}{3.2 .1} \\
\hline TFD (kg) & n chicks & 1.814 & 1.045 & 2.584 \\
\hline & iceberg $=\mathrm{Y}$ & -2.056 & -2.910 & -1.202 \\
\hline & IC & 0.332 & 0.106 & 0.558 \\
\hline & $\mathrm{IC}^{2}$ & -0.013 & -0.021 & -0.005 \\
\hline & Intercept & 1.373 & 0.205 & 2.540 \\
\hline 3.2 .2 & & & & \\
\hline PFM (kg) & iceberg $=\mathrm{Y}$ & -0.783 & -0.898 & -0.669 \\
\hline & IC & 0.018 & 0.011 & 0.025 \\
\hline & Intercept & 3.205 & 3.128 & 3.282 \\
\hline
\end{tabular}

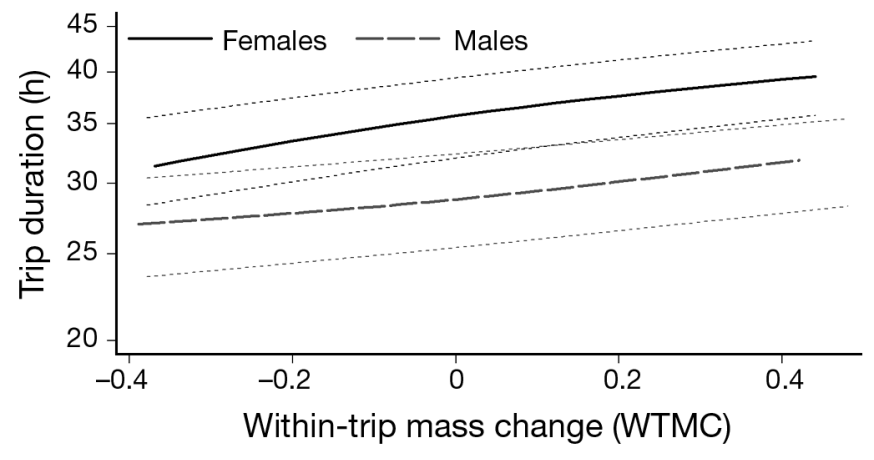

Fig. 2. Relationship between foraging trip duration (log scale: $\ln (\mathrm{FTD})$ ) and within-trip mass change (WTMC) of adult Adélie penguins as predicted by a mixed model controlling for random effects of individual identity and fixed effects of season and breeding stage; males and females compared. Dashed lines are 95\% CI. See Prediction 2.1.1 in Table 5 for model

of $\mathrm{AIC}_{\mathrm{c}}$ weight; $\beta$ (female) $=0.046,95 \% \mathrm{CI}=-0.022$ to $0.114)$ and number of chicks $(\beta=0.057,95 \% \mathrm{CI}=$ -0.002 to 0.117 ) were weaker as confidence intervals included zero (although just barely for number of chicks).

\section{Prediction 2.2}

FTD was positively correlated with previous trip duration (Table 5). Inclusion of $\ln$ (previous FTD) improved Model 2.1.1 substantially (decreased $\mathrm{AIC}_{\mathrm{C}}$ by 338.561; Table 4), although the direction of effect was contrary to prediction: FTD increased $0.47 \pm 0.03 \mathrm{~h}$ for every hour increase in the previous trip, i.e. longer foraging trips were followed by longer subsequent foraging trips. Over all 10 yr there was no consistent pattern of bimodality in trip duration within or among individuals. However, in 2 iceberg years $(2002,2003)$, bimodal patterns across all individuals were evident (Fig. 4). So there was a consistent pattern of bimodality across individuals in 2 years ( 2 of 5 iceberg years, 0 of 5 non-iceberg years).

\section{Prediction 2.3}

The selected model included a cubic effect of parent condition and also a small effect of sex, with females averaging $3.0 \pm 0.7 \%$ less mass gain per trip than males after controlling for a substantial effect of IM (Table 5, Fig. 5). Adding the interaction of sex and $\mathrm{RMC}_{\mathrm{i}}{ }^{3}$ did not improve the model, and the $95 \%$ confidence interval for the interaction term overlapped zero ( $\beta=0.14,95 \% \mathrm{CI}=-2.37$ to 2.66$)$. For every $10 \%$ heavier a parent began the season, it lost $1.2 \pm 0.1 \%$ more 

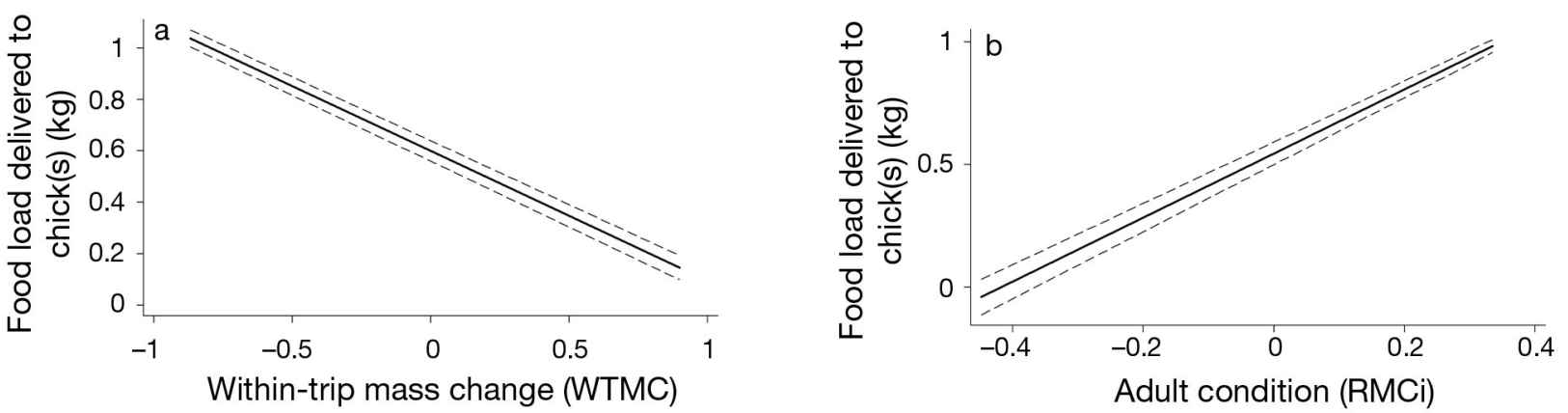

Fig. 3. Relationship between food delivered to Adélie penguin chick(s) on a given foraging trip to (a) within-trip mass change (WTMC) and (b) adult condition upon initiating the trip $\left(\mathrm{RMC}_{\mathrm{i}}\right)$, controlling for season and individual. Dashed lines are $95 \%$ CI. See Prediction 2.1.2 in Table 5 for model
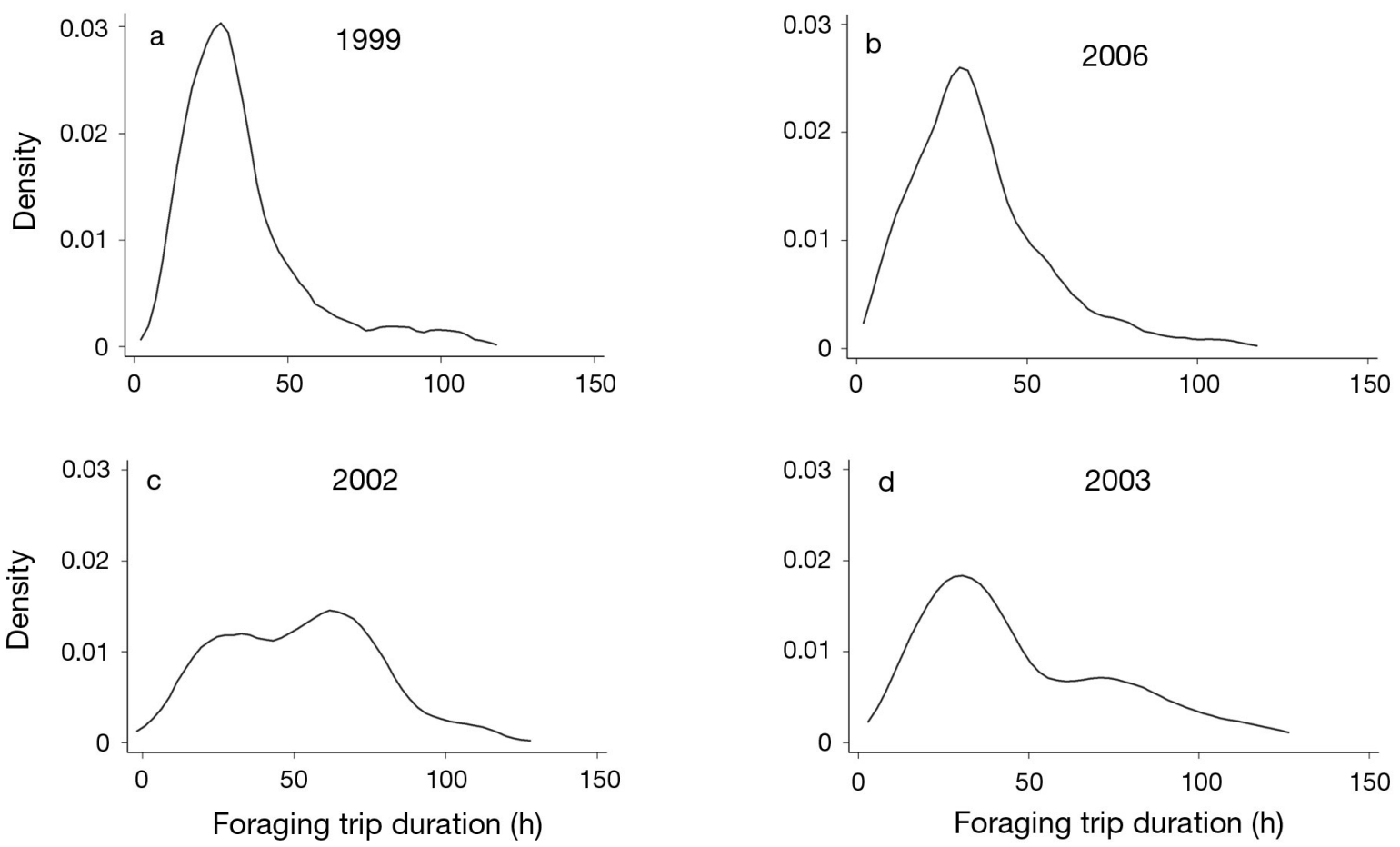

Fig. 4. Distribution of foraging trip durations of Adélie penguins for (a,b) 2 non-iceberg years (1999 and 2006) and (c,d) 2 iceberg years (2002 and 2003). The other 3 iceberg years did not show bimodality

per foraging trip. On average, parents who had positive WTMC (i.e. self-provisioned to some extent) on a given trip had lost $6.87 \pm 0.27 \%$ (males) to $8.81 \pm$ $0.32 \%$ (females) of their IM, with more mass gained per trip as a function of how much mass had been lost (Fig. 5). While the cubic term was retained in the strongest model, the bootstrapped $95 \%$ CI for the quadratic and cubic terms included zero, so we do not emphasize the non-linearity described by this model. The linear term $\left(\mathrm{RMC}_{\mathrm{i}}\right)$ revealed that for every $10 \%$ increase in $\mathrm{RMC}_{\mathrm{i}}$, WTMC increased by $6.7 \pm 0.58 \%$ (Table 5).

\section{Prediction 3}

Parents made longer trips when icebergs were present and shorter trips when sea ice concentration was higher (Table 5). The sea ice concentration effect was non-linear (i.e. the quadratic term was retained; Table 4), such that trip duration declined with increasing sea ice concentration until sea ice concentration reached $\sim 15 \%$, at which point trip duration increased (Fig. 6a). As predicted, females made longer trips than males and trips were longer during crèche than during the guard period (Table 5). 


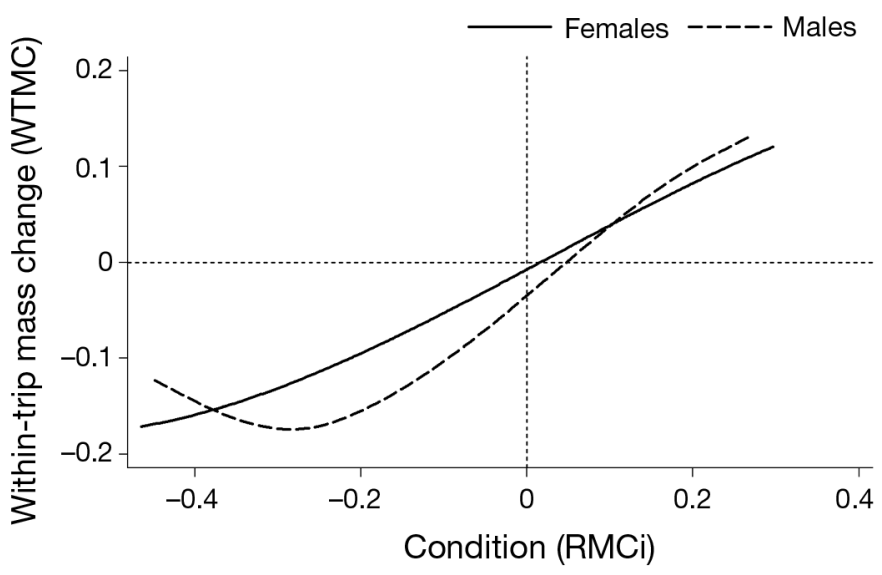

Fig. 5. Relationship between within-trip mass change (WTMC) of adult Adélie penguins on a foraging trip and individual condition $\left(\mathrm{RMC}_{\mathrm{i}}\right)_{\text {; }}$ males and females compared. Model predictions are from a mixed linear model controlling for penguin initial mass (i.e. mass at beginning of chick rearing). Despite different shapes of models fit independently by sex (shown), the model with common quadratic and cubic terms (but different intercepts) for the effect of $\mathrm{RMC}_{\mathrm{i}}$ on $\mathrm{WTMC}$ is better supported. See Prediction 2.3 in Table 5 for model

Contrary to prediction, parents lost $2.4 \pm 0.62 \%$ more of their IM (i.e. $2.4 \%$ higher $\mathrm{RMC}_{\mathrm{r}}$ ) during iceberg years compared with non-iceberg years, controlling for a positive effect of IM, a positive effect of sex $\left(\mathrm{RMC}_{\mathrm{r}}\right.$ more positive for females, also contrary to expectation), and a negative effect of breeding stage, as in the best model for Prediction 1 (parents began to regain a small amount of mass during crèche; Table 5). The iceberg effect on $\mathrm{RMC}_{\mathrm{r}}$ was not altered when 1997 was excluded from the model (which we checked because 1997 was a non-iceberg year that had anomalously low $\mathrm{RMC}_{\mathrm{r}}$ values). The number of chicks being fed was included in the second most competitive model $\left(\Delta_{\mathrm{i}}=\right.$ 0.55 ; Table 4 ), but had a relatively weak negative effect on $\mathrm{RMC}_{\mathrm{r}}(\beta=-0.010,95 \% \mathrm{CI}=-0.019$ to 0.004$)$. Sea ice concentration occurred in the third most competitive model $\left(\Delta_{\mathrm{i}}=0.644,18.6 \%\right.$ of $\mathrm{AIC}_{\mathrm{c}}$ weight; $\beta=$ $0.00071,95 \% \mathrm{CI}=-0.00005$ to 0.00189 ; Table 4 ), but the $95 \%$ CI included zero, so this was a relatively weak effect.

\section{Prediction 3.2}

The total amount of food delivered to chicks was related to the presence/absence of icebergs, mean sea ice concentration, and, as predicted, increased with the number of chicks (2-chick broods received $1.81 \pm$ $0.39 \mathrm{~kg}$ more total food per parent than 1-chick broods; Table 5). Chicks received $2.06 \pm 0.39 \mathrm{~kg}$ less food (per parent) overall during iceberg years than during non-iceberg years; sea ice concentration had a positive, non-linear effect on total food delivered until $\sim 12 \%$ cover, at which point the effect of higher sea ice concentration became negative during iceberg years and did not change during non-iceberg years (Fig 4b, Table 5). Contrary to predictions, sex was not included in the strongest model, although it did occur in the second best one $\left(\Delta_{\mathrm{i}}=2.20,24 \%\right.$ of $\mathrm{AIC}_{\mathrm{c}}$ weight). The estimate of the effect of sex was negative (i.e. females predicted to bring less total food) but the $95 \% \mathrm{CI}$ included zero $(\beta=-0.39,95 \% \mathrm{CI}=-1.11$ to 0.34 ).

Both the presence of icebergs and sea ice concentration had strong effects on chick pre-fledging mass (Table 5). Chick pre-fledging mass was $783 \pm 58 \mathrm{~g}$ lower in iceberg years; for every $1 \%$ more sea ice concentration, pre-fledging mass increased by $18 \pm 4 \mathrm{~g}$ (Table 5). The quadratic term for sea ice concentration was retained in the second best model $\left(\Delta_{i}=1.97,27 \%\right.$ of $\mathrm{AIC}_{\mathrm{c}}$ weight), but the effect was very weak ( $\beta=$ $-0.17,95 \% \mathrm{CI}=-1.45$ to 1.12 ).
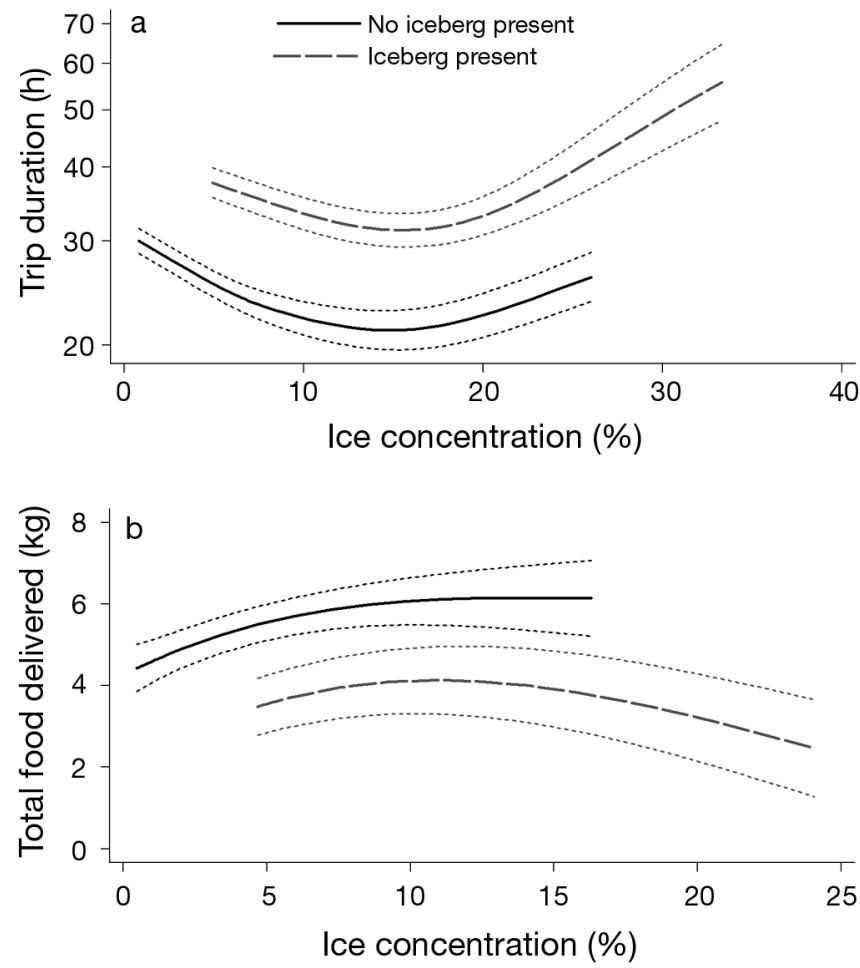

Fig. 6. Effect of sea ice concentration on (a) foraging trip duration and (b) food delivery to chicks of Adélie penguins with and without icebergs present. Results from mixed-effects generalized linear model controlling for random effect of parent identity and (a) fixed effects of sex and breeding stage or (b) fixed effect of number of chicks being fed. Dotted lines are $95 \%$ CI. See Predictions 3.2.1 \& 3.2.2 in Table 5 for models 


\section{DISCUSSION}

We have shown that Adélie penguins operate with an energetic cushion at the outset of breeding, almost always beginning with mass that they subsequently lose as they raise their chicks; the heavier an individual started, the larger a proportion of this mass it eventually lost. Later in the season, this cushion may be depleted. In fact, we observed that parents that had lost more than $\sim 8 \%$ of their IM made longer foraging trips and gained mass for themselves while bringing their chicks less food. Generally there was no bimodal pattern in trip duration; rather, trip durations increased as the season progressed and when demands of chicks were higher, supporting the interand intraspecific competition hypotheses presented previously (Ainley et al. 2004, 2006). Challenging environmental conditions (presence of giant icebergs) intensified these patterns (increased trip durations made it more likely that parents would lose mass, i.e. more positive RMC), reduced the amount of food brought to chicks, and decreased the chick pre-fledging mass. There was a more complex relationship with sea ice, with up to $\sim 12 \%$ cover coinciding with shorter trips and more food brought to chicks. Finally, parents with 2 chicks brought more food back than those with 1 chick.

\section{Hypothesis 1: adults in poor condition invest in self maintenance, which has negative consequences for chicks}

Our results confirm those of Chastel et al. (1995a, b), Weimerskirch et al. (1997, 2000, 2001), Vleck \& Vleck (2002), Takahashi et al. (2003), and Clarke et al. (2006), that relative body condition affects decision making in avian parents, following the predictions of life history theory: penguins in poorer condition made longer foraging trips, carried less food to young, and gained more mass per foraging trip than those in better condition. While previous researchers have hypothesized that longer foraging trips result in smaller food loads for Adélie penguin chicks (Drent \& Daan 1980, Clarke et al. 2002), ours is the first study to quantify this effect and the effect of adult body condition on this relationship.

Clarke (2001) and Clarke et al. (1998, 2002) found that female Adélie penguins at Bèchervaise Island, MacRobertson Land, a small colony of a few thousand pairs, showed a bimodal frequency distribution of short $(<40 \mathrm{~h})$ and long trips $(>40 \mathrm{~h})$, delivering more food after long trips than short trips, as subsequently predicted by Ropert-Coudert et al. (2004). In addition, females departing on long trips had lower body mass than those making short trips, implying that they decided to satisfy both their own and their chicks' energetic demands (Clarke et al. 1998, 2002). These patterns were interpreted as responses to the greater energetic debt incurred by females during the early breeding season (Chappell et al. 1993, Clarke et al. 1998, 2002, see also Ropert-Coudert et al. 2004, Angelier et al. 2008).

Our results support these findings, though we did not observe an alternating, bimodal strategy of long and short trips. We do not have structural or other physiological measures of these individuals with which to create alternative indices of condition, but mass alone has been shown to be a good index (Schamber et al. 2009), and low IM has been previously linked to poor physiological condition and higher corticosterone levels in Adélie penguins (Vleck \& Vleck 2002, Cockrem et al. 2006). The effectiveness of using proportional mass change in the absence of other condition measures is borne out in several ways by our results, beginning with the fact that during the one season when adult masses were initially lowest, RMC was negative. RMC was also negatively related to parents' FTD and WTMC, and positively related to chicks' meal sizes. All imply a trade-off between parental self-maintenance and chick investment, possibly mediated in part by chick demands (see also Erikstad et al. 1997, Ropert-Coudert et al. 2004, Varpe et al. 2004).

Clarke et al. (1998) found no evidence for a bimodal distribution of trip duration at another site, Edmonson Point, Ross Sea. Nor was there any evidence for bimodal trip durations at 3 widely spaced colonies in East Antarctica (Watanuki et al. 2002) or at Torgerson Island (Chappell et al. 1993), though in all cases males made shorter trips than females. Ropert-Coudert et al. (2004) observed bimodality in a single season, but did not study the effect of sex on trip duration, and only one foraging trip per individual was observed. The years we did observe bimodality were ones of extremely difficult conditions, and may reflect the distribution of trips made by high quality individuals (i.e. those that were able to forage efficiently) versus those made by low quality individuals (Lescroël et al. in press).

In all study locations mentioned above (Chappell et al. 1993, Watanuki et al. 2002, Ropert-Coudert et al. 2004) other than Bèchervaise Island (Clarke et al. 1998), penguins foraged principally or entirely in waters over the continental shelf, those being the richest of the Southern Ocean (Arrigo et al. 2003). The extremely narrow shelf off Bèchervaise Island, therefore, may offer 2 distinct foraging habitats within reach of the penguins as in the case of bimodal petrels (Weimerskirch et al. 1994). 


\section{Hypothesis 2: lower prey accessibility increases parents' investment in self-maintenance}

The effects of summer sea ice extent on Adélie penguin foraging behavior and breeding success have been previously evaluated (summarized in Ainley 2002): foraging trips are longest and breeding success lowest when ice cover is high. With the narrow shelf near Bèchervaise Island, extensive coastal fast ice limits penguin access to the richest (neritic) waters (Clarke et al. 2006, Emmerson \& Southwell 2008). Another study compared the small colony at Hukuro Cove $(<2000$ pairs), which had extensive fast ice (sea ice attached to land, with access to prey only available via sparse cracks), to colonies with more normal, loosely distributed pack ice at the (also small) Biomar colony and the larger Magnetic Island colony (17 200 pairs). Adélie penguins made longer trips to maintain their condition while feeding chicks less frequently at Magnetic Island, a site with (theoretically) much higher prey availability than Hukuro Cove (Watanuki et al. 2002). Possibly, the few penguins at Hukuro Cove competed far less for prey and consequently were able to maintain condition and feed young without confronting a trade-off. In contrast, penguins at Magnetic Island may have encountered prey depletion effects (cf. Ainley et al. 2004).

We observed high variability in trip duration, with the longest trips far exceeding those previously reported (e.g. Ropert-Coudert et al. 2004, Watanuki et al. 2004). A clear relationship existed between foraging parameters and sea ice concentration, which had a positive effect on trip duration and a negative effect on food loads when concentrations exceeded $\sim 12 \%$.

\section{CONCLUSIONS}

Given the importance of RMC and the similar negative correlation between parent mass and trip duration found previously (Clarke 2001, Watanuki et al. 2002), including in other seabird species (e.g. Chaurand \& Weimerskirch 1994b, Tveraa et al. 1998), it is important to account for the condition of individual breeding birds in order to best understand measures of parental investment, such as foraging trip duration and food loads obtained. It is also important to consider whether the range of conditions encountered during a study reveals the full range of the animals' foraging strategies when interpreting results (Weimerskirch et al. 2001), especially since a flexible investment strategy may be defined by the worst conditions (Ricklefs \& Schew 1994, Lescroël et al. in press). Such conditions should not occur very often, as otherwise the colony would cease to exist.
Previous studies finding foraging trips of variable distance and/or duration in seabirds according to parental condition have been in systems where 2 types of habitats were available for foraging. This contrasts the southern Ross Sea ecosystem of the present study, leading to interesting implications of the role of environment in shaping foraging strategies. In situations where distinct habitat types are available at discrete distances from the colony, trip durations may be more likely to be bimodally distributed, with intraspecific prey depletion less of a factor for the farther, pelagic habitat, and the nearer habitat exploited predominantly for provisioning young. If a single habitat is available, as in the present study, prey depletion may play an important role in determining foraging trip duration and, ultimately, foraging energetics, regardless of whether adults need to regain condition (see Ainley et al. 2004, 2006, Ballance et al. 2009).

There may be a threshold of trip duration which, if not surpassed, will hide the full suite of foraging strategies that could be employed once more desperate conditions are encountered. In Adélie penguins, that threshold may be $\sim 48 \mathrm{~h}$, a limit not reached in every year of the present study. Under the most challenging environmental conditions, chick mass suffered, as adults apparently prioritized self-maintenance. We conclude that penguins considered their own condition, adjusted their foraging effort, and regulated their body mass and food delivered to chicks relative to chick needs, environmental conditions, and corresponding availability of prey.

Acknowledgements. M. Beigel and N. Polish developed a weighbridge that operated well under challenging conditions. I. Gaffney, S. Heath, V. Toniolo, M. Hester, A. Lescroël, V. Marsaudon, V. Patil, R. Orben, L. Sheffield, S. Webb, J. Blum, B. Saenz, C. McCreedy, and K. Lindquist provided expert field assistance. A. Archer and staff at UC San Diego's Arctic and Antarctic Research Center assisted with acquiring satellite imagery. The US Antarctic Program and Antarctica New Zealand provided logistic support; financial support was provided by NSF grants OPP 9526865, 9814882, 0125608, and 0440643. G.B. received additional support from the University of Auckland, School of Biological Sciences. The prototype weighbridge was funded by the New Zealand Foundation for Research, Science, and Technology, grant CO 9527. We are grateful for the review of drafts by C. Barbraud, M. Hauber, A. Lescroël, S. Olmastroni, and 2 anonymous referees. This is PRBO contribution no. 1716.

\section{LITERATURE CITED}

Ainley DG (1972) Sexual size dimorphism in Adélie penguins. Ibis 114:267-271

Ainley DG (2002) The Adélie penguin: bellwether of climate change. Columbia University Press, New York

Ainley DG, Emison WB (1972) Sexual size dimorphism in Adélie penguins. Ibis 114:267-271 
Ainley DG, Schlatter RP (1972) Chick raising ability in Adélie penguins. Auk 89:559-566

Ainley DG, LeResche RE, Sladen WJL (1983) Breeding biology of the Adélie penguin. University of California Press, Berkeley

Ainley DG, Wilson P, Barton K, Ballard G, Nur N, Karl B (1998) Diet and foraging effort of Adélie penguins in relation to pack-ice conditions in the southern Ross Sea. Polar Biol 20:311-319

Ainley DG, Ballard K, Barton B, Karl G, Rau C, Ribic C, Wilson P (2003) Spatial and temporal variation of diet within a presumed metapopulation of Adélie penguins. Condor 105:95-106

- Ainley DG, Ribic CA, Ballard G, Heath S and others (2004) Geographic structure of Adélie penguin populations: overlap in colony-specific foraging areas. Ecol Monogr 74: $159-178$

Ainley DG, Ballard G, Dugger KM (2006) Competition among penguins and cetaceans reveals trophic cascades in the western Ross Sea, Antarctica. Ecology 87:2080-2093

- Angelier F, Bost CA, Giraudeau M, Bouteloup G, Dano S, Chastel O (2008) Corticosterone and foraging behavior in a diving seabird: the Adélie penguin (Pygoscelis adeliae). Gen Comp Endocrinol 156:134-144

Arrigo KR, van Dijken GL, Ainley DG, Fahnestock MA, Markus T (2002) Ecological impact of a large Antarctic iceberg. Geophys Res Lett 29:1104

Arrigo KR, Worthen DL, Robinson DH (2003) A coupled ocean-ecosystem model of the Ross Sea: 2. Iron regulation of phytoplankton taxonomic variability and primary production. J Geophys Res C 108:3231

Ballance LT, Ainley DG, Ballard G, Barton K (2009) An energetic correlate between colony size and foraging effort in seabirds, an example of the Adélie penguin Pygoscelis adeliae. J Avian Biol 40:279-288

Ballard G, Ainley D, Ribic C, Barton K (2001) Effect of instrument attachment and other factors on foraging trip duration and nesting success of Adélie penguins. Condor 103: 481-490

Ballard G, Toniolo V, Ainley DG, Parkinson CL, Arrigo KR, Trathan PN (in press) Responding to climate change: Adélie penguins confront astronomical and ocean boundaries. Ecology

Beaulieu M, Dervaux A, Thierry AM, Lazin D and others (2010) When sea-ice clock is ahead of Adélie penguins' clock. Funct Ecol 24:93-102

Becker PH, Wendeln H, González-Solís J (2001) Population dynamics, recruitment, individual quality and reproductive strategies in common terns Sterna hirundo marked with transponders. Ardea 89:241-252

Bolker BM, Brooks ME, Clark CJ, Geange SW, Poulsen JR, Stevens MHH, White JSS (2009) Generalized linear mixed models: a practical guide for ecology and evolution. Trends Ecol Evol 24:127-135

Booth AM, Minot EO, Fordham RA, Imber MJ (2000) Co-ordinated food provisioning in the little shearwater Puffinus assimilis haurakiensis: a previously undescribed foraging strategy in the Procellariidae. Ibis 142:144-146

Burnham KP, Anderson DR (2002) Model selection and multimodel inference: a practical information-theoretic approach, 2nd edn. Springer-Verlag, New York

Cavalieri D, Comiso J (2004) AMSR-E/Aqua daily L3 $12.5 \mathrm{~km}$ $\mathrm{Tb}$, sea ice conc., and snow depth polar grids V001, March to June 2004. National Snow Ice Data Center, Boulder, CO (http://nsidc.org/data/docs/daac/ae_si12_12km_tb_sea_ice_ and_snow.gd.html)

Cavalieri D, Parkinson C, Gloersen P, Zwally HJ (1996). Sea ice concentrations from Nimbus-7 SMMR and DMSP SSM/I passive microwave data, Dec. 17, 1997 to Jan. 22 2007. National Snow Ice Data Center, Boulder, CO (http:// nsidc.org/data/nsidc-0051.html)

> Chappell MA, Janes DN, Shoemaker VH, Bucher TL, Maloney SK (1993) Reproductive effort in Adélie penguins. Behav Ecol Sociobiol 33:173-182

Chastel O, Weimerskirch H, Jouventin P (1995a) Influence of body condition on reproductive decision and reproductive success in the blue petrel. Auk 112:964-972

> Chastel O, Weimerskirch H, Jouventin P (1995b) Body condition and seabird reproductive performance: a study of three petrel species. Ecology 76:2240-2246

Chaurand T, Weimerskirch H (1994a) Incubation routine, body mass regulation and egg-neglect in the blue petrel Halobaena coerulea. Ibis 136:285-290

Chaurand T, Weimerskirch H (1994b) The regular alternation of short and long foraging trips in the blue petrel Halobaena caerulea: a previously undescribed strategy of food provisioning in a pelagic seabird. J Anim Ecol 63: $275-282$

Clarke JR (2001) Partitioning of foraging effort in Adélie penguins feeding chicks at Bèchervaise Island, Antarctica. Polar Biol 24:16-20

Clarke JR, Manly B, Kerry K, Gardner H, Franchi E, Corsolini S, Focardi S (1998) Sex differences in Adélie penguin foraging strategies. Polar Biol 20:248-258

Clarke JR, Kerry K, Irvine L, Phillips B (2002) Chick provisioning and breeding success of Adélie penguins at Béchervaise Island over eight successive seasons. Polar Biol 25: 21-30

Clarke JR, Emmerson LM, Otahal P (2006) Environmental conditions and life history constraints determine foraging range in breeding Adélie penguins. Mar Ecol Prog Ser 310:247-261

Cockrem JF, Potter MA, Candy EJ (2006) Corticosterone in relation to body mass in Adélie penguins (Pygoscelis adeliae) affected by unusual sea ice conditions at Ross Island, Antarctica. Gen Comp Endocrinol 149:244-252

Drent R, Daan S (1980) The prudent parent: energetic adjustment in avian breeding. Ardea 68:225-252

Dugger KM, Ballard G, Ainley DG, Barton KJ (2006) Effects of flipper bands on foraging behaviour and survival of Adélie penguins (Pygoscelis adeliae). Auk 123:858-869

> Emmerson L, Southwell C (2008) Sea ice cover and its influence on Adélie penguin reproductive performance. Ecology 89:2096-2102

- Erikstad KE, Asheim M, Fauchald P, Dahlhaug L, Tveraa T, Dahlhaug P (1997) Adjustment of parental effort in the puffin; the roles of adult body condition and chick size. Behav Ecol Sociobiol 40:95-100

Erikstad KE, Fauchald P, Tveraa T, Steen H (1998) On the cost of reproduction in long-lived birds: the influence of environmental variability. Ecology 79:1781-1788

> Freed LA (1981) Loss of mass in breeding wrens: Stress or adaptation? Ecology 62:1179-1186

Golet GH, Irons DB, Estes JA (1998) Survival costs of chick rearing in black-legged kittiwakes. J Anim Ecol 67: $827-841$

Golet GH, Schmutz JA, Irons DB, Estes JA (2004) Determinants of reproductive costs in the long-lived black-legged kittiwake: a multiyear experiment. Ecol Monogr 74: 353-372

> Goodman D (1974) Natural selection and a cost ceiling on reproductive effort. Am Nat 108:247-268

> Granadeiro JP, Nunes M, Silva MC, Furness RW (1998) Flexible foraging strategy of Cory's shearwater, Calonectris 
diomedea, during the chick-rearing period. Anim Behav 56:1169-1176

Kerry K, Agnew D, Clarke J, Else G (1992) Use of morphometric parameters for the determination of sex of Adélie penguins. Wildl Res 19:657-664

Kerry KR, Clarke JR, Else GD (1993) The use of an automated weighing and recording system for the study of the biology of Adélie penguins (Pygoscelis adeliae). Proc NIPR Symp Polar Biol 6:62-75

Lack D (1968) Adaptations for breeding in birds. Methuen, London

Lescroël A, Ballard G, Toniolo V, Barton KJ, Wilson PR, Lyver PO, Ainley DG (in press) Working less to gain more: when breeding quality relates to foraging efficiency. Ecology

Lessells CM (1991) The evolution of life histories. In: Krebs JR, Davies NB (eds) Behavioural ecology: an evolutionary approach, 3rd edn. Blackwell, Oxford, p 32-68

Massom RA, Stammerjohn SE, Smith RC, Pook MJ and others (2006) Extreme anomalous atmospheric circulation in the West Antarctic Peninsula region in austral spring and summer 2001/02, and its profound impact on sea ice and biota. J Clim 19:3544-3571

NASA (2007) MODIS Rapid Response System, Ross Sea subset. Available at http://rapidfire.sci.gsfc.nasa.gov/subsets/ index.php?subset=RossSea

Norberg RA (1981) Temporary weight decrease in breeding birds may result in more fledged young. Am Nat 118: 838-850

Nur N (1984a) Feeding frequencies of nestling blue tits (Parus caeruleus): costs, benefits and a model of optimal feeding frequency. Oecologia 65:125-137

$>$ Nur N (1984b) The consequences of brood size for breeding blue tits. I. Adult survival, weight change and the cost of reproduction. J Anim Ecol 53:479-496

Nur N (1986) Is clutch size variation in the blue tit (Parus caeruleus) adaptive? An experimental study. J Anim Ecol 55:983-999

Nur N (1987) Parents, nestlings and feeding frequency: a model of optimal parental investment and implications for avian reproductive strategies. In: Kamil A, Krebs JR, Pulliam HR (eds) Foraging behavior. Plenum Press, New York, p 457-475

Orians GH, Pearson NE (1979) On the theory of central place foraging. In: Horn DJ, Mitchell RD, Stairs GR (eds) Analysis of ecological systems. Ohio State University Press, Columbus, p 154-77

Pennycuick CJ, Croxall JP, Prince PA (1984) Scaling of foraging radius and growth rate in petrels and albatrosses (Procellariiformes). Ornis Scand 15:145-154

Perrins CM, Moss D (1975) Reproductive rates in the great tit. J Anim Ecol 44:695-706

Rabe-Hesketh S, Skrondal A (2008) Multilevel and longitudinal modeling using Stata, 2nd edn. Stata Press, College Station, TX

Ricklefs RE, Schew WA (1994) Foraging stochasticity and lipid accumulation by nestling petrels. Funct Ecol 8:159-170

$>$ Ropert-Coudert Y, Wilson RP, Daunt F, Kato A (2004) Patterns of energy acquisition by a central place forager: benefits of alternating short and long foraging trips. Behav Ecol 15: $824-830$

Schamber JL, Esler D, Flint PL (2009) Evaluating the validity of using unverified indices of body condition. J Avian Biol 40:49-56

Editorial responsibility: Rory Wilson,

Swansea, UK
Shepherd LD, Millar CD, Ballard G, Ainley DG and others (2005) Microevolution and mega-icebergs in the Antarctic. Proc Natl Acad Sci USA 102:16717-16722

Stearns SC (1976) Life-history tactics: a review of the ideas. Q Rev Biol 51:3-47

Takahashi A, Watanuki Y, Sato K, Kato A, Arai N, Nishikawa J, Naito Y (2003) Parental foraging effort and offspring growth in Adélie penguins: Does working hard improve reproductive success? Funct Ecol 17:590-597

Tveraa T, Saether B, Aanes R, Erikstad KE (1998) Regulation of food provisioning in the Antarctic petrel; the importance of parental body condition and chick body mass. J Anim Ecol 67:699-704

> Varpe Ø, Tveraa T, Fostad I (2004) State-dependent parental care in the Antarctic petrel: responses to manipulated chick age during early chick rearing. Oikos 106:479-488

Vleck CM, Vleck D (2002) Physiological condition and reproductive consequences in Adélie penguins. Integr Comp Biol 42:76-83

Watanuki Y, Kato A, Sato K, Niizuma Y, Bost CA, Le Maho Y, Naito Y (2002) Parental mass change and food provisioning in Adélie penguins rearing young in colonies of contrasting sea-ice conditions. Polar Biol 25:672-681

Watanuki Y, Takahashi A, Sato K, Kato A, Bost CA (2004) Inter-colony and sex differences in the effects of parental body condition and foraging effort on the brood growth of Adélie penguins. J Ethol 22:91-98

Weimerskirch H (1998) How can a pelagic seabird provision its chick when relying on a distant food resource? Cyclic attendance at the colony, foraging decision and body condition in sooty shearwaters. J Anim Ecol 67:99-109

Weimerskirch H, Chastel O, Ackermann L, Chaurand T, Cuenjot-Chaillet F, Hindermeyer X, Judas J (1994) Alternate long and short foraging trips in pelagic seabird parents. Anim Behav 47:472-476

Weimerskirch H, Cherel Y, Cuenot-Chaillet F, Ridoux V (1997) Alternative foraging strategies and resource allocation by male and female wandering albatrosses. Ecology 78:2051-2063

Weimerskirch H, Prince PA, Zimmermann L (2000) Chick provisioning by the yellow-nosed albatross Diomedea chlororhynchos: response of foraging effort to experimentally increased costs and demands. Ibis 142:103-110

Weimerskirch H, Zimmermann L, Prince PA (2001) Influence of environmental variability on breeding effort in a longlived seabird, the yellow-nosed albatross. Behav Ecol 12: 22-30

> Weimerskirch H, Ancel A, Caloin M, Zahariev A, Spagiari J, Kersten M, Chastel O (2003) Foraging efficiency and adjustment of energy expenditure in a pelagic seabird provisioning its chick. J Anim Ecol 72:500-508

Williams GC (1966) Natural selection, the costs of reproduction and a refinement of Lack's principle. Am Nat 100: $687-690$

Williams TD (1995) The penguins. Oxford University Press, Oxford

Wooller RD, Coulson JC (1977) Factors affecting the age of first breeding of the kittiwake Rissa tridactyla. Ibis 119: 339-349

Ydenberg RC, Welham CVJ, Schmid-Hempel R, SchmidHempel P, Beauchamp G (1994) Time and energy constraints and the relationships between currencies in foraging theory. Behav Ecol 5:28-34

Submitted: November 11, 2009; Accepted: January 25, 2010

Proofs received from author(s): April 21, 2010 